\title{
Principios educativos de la educación occidental: la Edad Media
}

\author{
MANUEL LÁZARO PULIDO \\ Universidad Bernardo O'Higgins, Región Metropolitana, Chile
}

RESUMEN

La Edad Media es una época extensísima de tiempo que afrontó el reto de mantener la riqueza heredada del periodo anterior, preparando los elementos de la pedagogía occidental. Este artículo pretende presentar los elementos fundamentales de la educación medieval. Describimos el sistema organizativo de la enseñanza y las diferentes instituciones, el papel de los agentes de la educación, el currículo de enseñanza y las herramientas materiales y formales. En la Edad Media la institución más conocida es la universidad, pero de ella no nos vamos a ocupar directamente, sino que vamos a exponer aquellos elementos que explican una máxima en el desarrollo de las ideas y la historia: la originalidad de un hecho significativo siempre acontece en un contexto que lo posibilita y del que al menos es razón suficiente.

PALABRAS CLAVE

educación medieval; instituciones medievales; metodología medieval. 


\title{
EDUCATIONAL PRINCIPLES OF OCCIDENTAL EDUCATION: THE MIDDLE AGE
}

\begin{abstract}
Middle Age is an extensive time period what took up the challenge to keep the richness of time before, and prepare the occidental pedagogy elements. This paper wants to present the fundamental elements of medieval education. We describe the organisational system and the different institutions, the education agent role, the educational curriculum, and the material and formal tools. In the Middle Age, University is the most important institution, but we going to study specially the elements that explain the development of ideas and history: the originality of significant fact is present always in a context.
\end{abstract}

KEYWORDS

medieval education; medieval institutions; medieval methodology.

\section{PRINCÍPIOS EDUCATIVOS DA EDUCAÇÃO OCIDENTAL: A IDADE MÉDIA}

\author{
RESUMO
}

A Idade Média é um período de tempo muito extenso, que enfrentou o desafio de manter a riqueza herdada do período anterior, preparando os elementos da pedagogia ocidental. Este artigo pretende apresentar os elementos fundamentais da educação medieval. Descrevemos o sistema organizativo do ensino e as diferentes instituições, o papel dos agentes de educação, o currículo de ensino, bem como as ferramentas materiais e formais. Na Idade Média, a instituição mais conhecida é a universidade, mas dela não nos ocuparemos diretamente; exporemos antes os elementos que explicam uma máxima no desenvolvimento das ideias e da história: a originalidade de um fato significativo acontece sempre em um contexto que o possibilita e do qual, pelo menos, é razão suficiente.

PALAVRAS-CHAVE

educação medieval; instituições medievais; metodologia medieval. 


\section{INTRODUCCIÓN. LA EDUCACIÓN EN LA EDAD MEDIA}

La Edad Media es uno de los períodos de la historia con más lugares comunes, muchos de ellos de carácter peyorativo. El propio nombre "Edad Media" responde a la crítica realizada por los humanistas al método escolástico en un tiempo en el que no podía responder a los retos intelectuales y cuestiones planteadas de forma novedosa. La virulencia empleada se debe en gran medida a las resistencias que la escolástica ofreció al cambio del modelo educativo promulgado por los nuevos intelectuales, y que se acentuó en el Concilio de Trento. Pero lo que los estudios muestran (García 1999, p. 473-499) es que nos encontramos ante una época de contenidos de valor propios por sí mismos y de una proyección ineludible para la comprensión de la historia del pensamiento en Occidente. Quizás es el aspecto educativo el instrumento catalizador de la expansión del pensamiento medieval y configurador del mundo occidental que conocemos.

En la exposición de los diversos elementos educativos hemos de tener en cuenta su extensión temporal que podemos dividir en dos grandes momentos a los que iremos haciendo referencia:

- La Alta Edad Media (ss. VI-XI) gestiona los ecos del final de la Edad Antigua, y la dialéctica mantenida con la irrupción de los pueblos bárbaros. Los estudios (AA.VV. 1972) señalan que desde el punto de vista educativo supone un cambio del modelo institucional (las escuelas existentes en el mundo grecorromano) y de los agentes de la educación, textos y métodos fundamentales. No existe una ruptura traumática con la herencia grecorromana, pero sí un cambio debido al triunfo del cristianismo como agente de cultura y educación.

El cristianismo no se alzó como enemigo de los nuevos pueblos, sino que vio en ellos una ocasión de transformación. Rescató los elementos culturales de la época clásica como herramientas propedéuticas de entendimiento de la fe cristiana al servicio de la conversión del pueblo bárbaro. A través del modelo formativo pervivió parte de la cultura humanista grecolatino y se desarrollaron elementos propios. La enseñanza laica y eclesiástica fue tomando forma, poco a poco el peso de la balanza se inclinó a la segunda, pero sin confundirse. A medida en que el mundo feudal se va imponiendo, la escuela urbana deja paso a otras escuelas. Este período conoce su momento clave en la época carolingia, destacando la figura de Alcuino de York (730-804) y su influjo desde el célebre monasterio de Saint-Martin de Tours, quien muestra una meta educativa en la Corte de Aquisgrán que estará presente en la educación medieval: hacer posible una nueva Atenas, en su juicio con más esplendor, al estar ennoblecida por la enseñanza de Cristo, superando así la Academia griega a través del estudio cuidado de los textos - encíclica De litteris colendis - (Boretius, 1883, p. 52-53).

- La Baja Edad Media (siglos XII-XIV) supone el afianzamiento de las bases educativas del primer periodo medieval. En el siglo XII — época de Renacimiento - (Haskins, 1928; Verger, 1996) se impulsa el pen- 
samiento filosófico y teológico, a partir de la renovación de las escuelas existentes al ritmo de la sociedad cambiante. Impulso que culmina en el siglo XIII con la llegada de tres elementos fundamentales: 1) la cristalización de las escuelas con el nacimiento de las universidades, 2) el papel desarrollado por las nuevas necesidades pastorales e intelectuales de la Iglesia (IV Concilio Eecuménico de Letrán) de las Órdenes Mendicantes y el desarrollo de los Estudios Generales, y 3) la llegada al mundo latino (escuelas de traductores) de la totalidad de la obra de Aristóteles (corpus aristotelicum), el cambio del horizonte filosófico-científico y las herramientas pedagógicas (protagonismo de los instrumentos racionales, desarrollo del lenguaje lógico y la consolidación del método escolástico). Este impulso se convertirá crítico en el siglo XIV, suponiendo una ruptura que anuncia el advenimiento de un nuevo pensamiento filosófico y político.

\section{SISTEMA ORGANIZATIVO}

Cuando recordamos el sistema educativo en la Edad Media nos viene a la memoria el nacimiento de las universidades, pero esta institución no nació de la nada. Existía un entramado consolidado que refleja una institucionalización de la enseñanza. Junto a la enseñanza reglada en instituciones escolares existían otros vehículos de instrucción.

Podemos hablar de un entramado organizativo estructurado que responde en la mayoría de las ocasiones más a las necesidades que a una planificación. A pesar de esto es innegable el peso escolar, así la emblemática Universidad de París (Universitas magistrorum et sc(b)olarium Parisiensis) ${ }^{1}$ tiene su etiología en el impulso que las escuelas urbanas alcanzaron en el siglo XII, tratándose en principio de una corporación de profesores y alumnos que aparece en París como complemento de la escuela de teología de Notre-Dame. La aprobación del rey Felipe II a estas escuelas supuso que se reunieran los maestros y alumnos pertenecientes a estas escuelas bajo la autoridad y jurisdicción de un canciller. El privilegio real presumió la concesión del fuero eclesiástico, es decir, la posibilidad de poder ser juzgados bajo la autoridad eclesiástica y no civil. De este modo, la nueva institución educativa se organizó en torno a cuatro Facultades: una que era de contenido básico o general: la Facultad de Artes Liberales; y tres especializadas: derecho canónico o decretales, medicina y teología. Esta organización universitaria conocía precedentes en el s. XII como la existencia de las naciones (nationes), es decir, una organización corporativa de los maestros y estudiantes según el origen o región, al igual que la facultad.

La educación hereda de la Antigüedad tardía el concepto de escuela (en griego sjolé). Aunque estamos presentando de forma general el desarrollo de los diversos elementos presentes en la educación medieval, es necesario señalar la enorme

1 Inocencio III utiliza la fórmula "Universis magistris et scolaribus Parisiensibus" ya en 1205 (Denifle y Châtelain, 1880, p. 62). 
complejidad del desarrollo de las diferentes formas educativas, métodos, didácticas, organizaciones... La escuela medieval (sc(h)ola) designa tanto el lugar donde se desarrolla el proceso de enseñanza como un modelo de estudio que se distingue del desarrollo posterior, especialmente a partir del siglo XIII con el nacimiento de los estudios (studia) y la universidad.

Durante la Edad Media se irán desarrollando diferentes tipos de escuelas dependiendo del lugar y el modo de enseñanza. Estas escuelas van sustituyendo las instituciones educativas de la Antigüedad - las escuelas urbanas - de naturaleza municipal o privada que van sobreviviendo en los lugares más romanizados y que tras el decreto de Justiniano quedan abolidas en su formato "pagano" (la Academia platónica de Atenas se cierra en el 529). Los estudios muestran que la escuela no desapareció, sino que se fue trasformando (Sot y Riché, 1990), combinando formación teológica con servicio pastoral. El texto fundamental es la Biblia, pero el estudio de la Sagrada Escritura pasa por una serie de lecturas que comprenderán el entendimiento teológico - racional - de la Revelación y sabiduría de vida. La hermenéutica bíblica realizada desde la teología precisaba de los elementos racionales, a saber, la cultura antigua en la que se fueron desarrollando las primeras escuelas catequéticas, especialmente las alejandrinas. Desaparecidas las escuelas antiguas, las escuelas nacidas en la Edad Media tendrán que fomentar el estudio de la cultura grecolatina como herramienta necesaria para la formación cristiana. Las escuelas públicas van cayendo en decadencia. En el ámbito eclesial sabemos de la existencia de las escuelas presbiterales (o clericales) - siglo VI - que se dedicaban a la formación de los futuros clérigos, aunque no se conoce si solo formaban a los futuros sacerdotes o también acogían en su seno a otros niños.

Diversos acontecimientos socio-culturales como la llegada del Islam, las guerras en tierras italianas, o el debilitamiento de la monarquía en Galia, provocan un cambio en las costumbres y un cierto desconcierto administrativo y educativo que merecerán una respuesta cuando la ocasión lo propicie, es lo que se conoce como renacimiento carolingio, cuyo fruto más propio es la Academia y la escuela palatina pero que supone una promoción del sistema educativo en general y los diversos tipos de escuela existentes.

\section{LA ESCUELA PALATINA}

La escuela palatina, anexa a la corte (palatium), nace del empeño de Carlomagno por devolver al clero la dignidad fundada en una sólida formación intelectual y un comportamiento moral. Para ello utiliza textos legislativos y personas que juzga adecuadas y hace de la Academia palatina lugar de encuentro de sabios y eruditos. La labor fue confiada en el 781 a Alcuino de York, quien había sido formado en la escuela episcopal de Jarrow. ${ }^{2}$ Su impulso tuvo reflejo en el establecimiento de numerosas escuelas episcopales y monásticas. Carlomagno pide organizar "escuelas de lectura para los jóvenes en cada monasterio e obispado, donde se puedan aprender

2 Escuela fundada por Beda el Venerable (674-735). 
los salmos, las notas, el canto, el cálculo, la gramática, y encontrar los libros canónicos con corrección esmerada [...]" (Boretius, 1883, p. 65). Se trata de una promoción cultural que afecta a las instituciones educativas y culturales y a la realización de libros de calidad. El surgimiento de la escuela palatina implicará la revalorización del estudio de los clásicos para entender la Biblia, recensionada por el propio Alcuino y el establecimiento de las bases curriculares asentadas en el estudio de las artes liberales como disciplinas propedéuticas del estudio superior de la Biblia.

El renacimiento carolingio involucraba una reforma de la educación que se refleja en la enseñanza monástica y en la formación de los laicos. Carlomagno está convencido de la importancia de una cuidada instrucción para el desempeño de las responsabilidades administrativas. La formación laica se hace en la Academia palatina, espacio de reunión y de discusión de cuestiones religiosas y profanas, que representa la institución de la escuela del palacio, ámbito de formación de los nuevos administrativos, juristas y burócratas de la Corte. En el siglo IX aparecen resquicios en ciertas cortes como la de Carlos el Calvo (823-977) donde se discuten cuestiones de alta especulación teológica y se impulsan los estudios y traducciones de las fuentes griegas como las de Juan Escoto Eriúgena (810-877). Las escuelas palatinas, como las monásticas y las eclesiásticas, irán realizando regulaciones ("espejos" de laicos) en las que no se olvidará la enseñanza moral (Dhuoda, 1975, p. 225). Con el tiempo se va imponiendo la forma rural que afecta a las escuelas urbanas y en ellas las laicales (comunales), surgiendo la sustitución de la escuela civil por la escuela eclesiástica.

\section{LA ESCUELA MONÁSTICA O CLAUSTRAL}

La escuela monástica es el elemento más característico de la educación medieval (Bardy, 1953). Introduce elementos culturales derivados de la enseñanza clásica jugando un papel de primera magnitud en el desarrollo de la cultura. En Inglaterra los aristócratas inician sus estudios en las escuelas de los monasterios. Los monasterios se constituyen en faros de irradiación cultural: Monte Casino en Italia, Saint-Martin de Tours o Saint Denis en Francia, Reichenau en Alemania. Cuando en el siglo $\mathrm{X}$ parece haber un relajamiento en la vida intelectual medieval, los monasterios seguirán manteniendo el pulso cultural y educativo, y aparecen figuras personales como Odón (926-942) que hará renacer con fuerza experiencias monásticas como Cluny (Riché, 1976, p. 27-42).

La escuela monástica encuentra su divisa en el principio benedictino (ora et labora) que procura a los monjes un conocimiento propicio dependiendo de sus capacidades. Para tal fin fueron adaptando los principios pedagógicos de la Antigüedad a sus necesidades formativas (intelectuales, religiosas, espirituales).

Obviamente la división entre monjes instruidos y no instruidos dependía en gran modo del bagaje intelectual y de origen con el que se ingresara en el monasterio. Pero aun así los monasterios tenían una escuela para los infantes llegados. La formación como alumno y novicio era de intensidad, sin distracciones y con escasos signos de indisciplina. 
La influencia de las escuelas monacales reside en constituirse en focos aislados de cultura de gran significatividad educativa y cultural (enseñanza, biblioteca, escritorios...), en ser una escuela "interna" (Verdú, 2014), y en proponer una enseñanza a oyentes externos (escuela "externa”). Las escuelas monásticas, junto a todo el sistema de enseñanza, pasarán una crisis en el siglo XI y parte del XII, salvo excepciones (la Escuela de Saint-Víctor), pues las tendencias místicas y las reformas de búsqueda espiritual tendieron a olvidar e incluso desdeñar el estudio como herramienta de fortaleza moral y de sabiduría cristiana, el gran fin de la educación (camaldulenses, cisterciensens, premonstratenses, cartujos, etc.). ${ }^{3}$ La recuperación en el siglo XII sin embargo terminará por introducir cambios como el cerrar la escuela "externa" a finales del siglo XII.

\section{LA ESCUELA URBANA: LA ESCUELA COMUNAL Y LA ESCUELA CATEDRALICIA O LECTURAL}

Entendemos la escuela urbana como aquella que se encuentra en el entorno de un espacio habitado urbano y con un sistema complejo de convivencia común, diferenciado de un espacio rural, menos habitado o casi deshabitado. Las escuelas urbanas son en la Edad Media en su mayoría eclesiásticas, pero también existieron escuelas públicas o laicales (1lamadas comunales).

En la medida en que la Edad Media se va volviendo más rural y tras los decretos de abolición de las escuelas paganas, la escuela urbana y pública decayó, sin embargo, tras el impulso carolingio y en espacios urbanos, los aristócratas seguían acudiendo a ellas, pues eran claves en la formación de los cuadros administrativos (tribunales pública, vida política...). Durante el periodo tardo-imperial el estado ejerce un mayor control sobre estas escuelas lo que supone una reducción de su autonomía. Su suerte va en paralelo al destino de la aristocracia urbana, en el sentido de que su sustitución por la nueva aristocracia militar y burocrática afectará también a las instituciones formativas, especialmente en lo que respecta al control por parte de las autoridades. Sabemos que, en las escuelas comunales, en el siglo XI, existe un desarrollo especialmente significativo de las disciplinas del trivium y del derecho, pues eran medios necesarios para desarrollar una buena carrera en la administración pública y que a los clérigos les gustaba la asistencia a la misma. Las escuelas comunales (laicas) pervivirán apegadas a los fines de la administración. En Italia existe de forma significativa escuelas para el aprendizaje del oficio de Notarios (ej. Pavía y Bolonia) y de medicina (significativamente Salerno).

La escuela urbana vinculada a la catedral (catedralicia, lectoral o episcopal) fue impulsada en el siglo IX a instancias de los soberanos carolingios. La necesidad de formar un clero capaz de cumplir su papel de liderazgo religiosos y político que

3 Como señala Philippe Delhaye (1947, p. 228) llegó a ser opinión común entre los monjes del siglo XII: "En fin, podemos decir que la opinión común en el mundo monástico del siglo XII, es que la función docente es incompatible con el estado de vida monástico". 
pudiera uniformizar la cultura e impulsar la administración exige una sólida formación, capaz de preparar a la lectura de las diversas escrituras (manuscritos y códices), comprender e interpretarlas adecuadamente. En el siglo X las escuelas episcopales eran numerosas y activas en Italia y fueron implementándose en Alemania de la mano de la figura política de Otón el Grande (912-973), y sin brillar en exceso aparecen en Francia, toda vez que la autoridad real no conoce tanta fuerza. Aun así aparecen escuelas que tendrán una gran repercusión como es el caso de Reims y, sobre todo, Chartres (Clerval, 1895).

A finales del siglo XI la escuela escolástica se reactiva en una lucha por el control del poder y alcanza un nivel educativo que sobrepasa la enseñanza básica y media, con una metodología activa y racional. Diversos concilios - Roma en 1079, III (Alejandro III, 1179) y IV de Letrán (Inocencio III, 1215) - realizan un nuevo esfuerzo de reorganización, precisando normas sobre el deber de los maestros e impulsando la legislatura escolástica. La escuela eclesiástica recupera la enseñanza de los no oblatos, se abre a la burguesía como el nuevo protagonista de la sociedad de la Baja Edad Media y decide tomar el protagonismo educativo de la nueva clase social emergente. La escuela catedralicia conocerá un momento de esplendor y protagonismo emanado de la autoridad del obispo. El III concilio ecuménico de Letrán (1179) impulsa la autoridad episcopal al conceder al cabildo la "licentiam docendi" y la supervisión de los maestros. Ello hará que emerja la tensión entre la libertad de enseñanza y la necesidad de control y organización por parte de las autoridades, en este caso eclesiásticas.

\section{OTROS CENTROS}

Junto a estas escuelas existen otras experiencias de enseñanza como las escuelas de gramática de instrucción básica se centraban en el trivium y preparaban para el culto.

Otras que se dedicaban a la enseñanza oficial, a la de un oficio determinado de importancia cultural fueron las escuelas de copistas o los scriptoria (talleres de copistas). Jugaron un importante papel de trasmisión cultural, tanto de la cultura libresca, como en la capacidad de mantener el pulso de la lectura común. Los estudios paleográficos denominan a la escritura forjada en esta época medieval y apegada a las escuelas de copistas bajo el nombre de escritura carolingia (unida por lo tanto a la escuela palatina), de gran significación: "ninguna más importante que esta, pues de ella proceden hasta hoy todas las que vinieron después" (Marín, 1991, p. 90). Nacida para los códices con una escritura regular y constante se extendió a los documentos con una escritura más irregular (Carlomagno deseaba que los manuscritos fueran copiados por escribanos profesionales que hicieran una letra que fuera legible para todos y unificara la lectura para su comprensión posterior). Esta escritura dominará con variaciones y particularidades en el tiempo hasta finales del siglo XII y el siglo XIII cuando la llamada escritura gótica triunfe al albur de la extensión de la cultura, la proliferación de los estudios y el nacimiento de las universidades que exigirán una letra más espontánea y una mayor utilización del papel frente al pergamino. 
La universidad hereda la tradición escolar y queda jurídicamente definida bajo el nombre de universitas o studium generale, tal como utiliza el término el papa Inocencio IV (1243-1254). Junto a la institución universitaria que tienen como centros más prestigiosos y antiguos a Bolonia, París, Montpellier y Oxford, aparecen en los siglos XIII y XIV los estudios (studia): los lugares de estudios (escuelas conventuales) de las Órdenes mendicantes, a saber, la Orden de Predicadores, la Orden de Hermanos Menores (franciscanos), los Eremitas de San Agustín y los Carmelitas. Estas escuelas se dedican a formar los lectores que cada convento debe poseer para garantizar la formación de la comunidad y el cuidado pastoral. Se constituye una red de educación en la que se pueden observar diversos niveles jerarquizados de enseñanza:

- los studia, centros preparatorios en los que los hermanos estudian las artes liberales;

- los studia solemnia, para completar la formación teológica de los futuros lectores;

- studia generalia, los centros universitarios más importantes donde estudian becados los hermanos más dotados.

Otros centros son los dedicados al aprendizaje de las diferentes lenguas diferentes: studia linguarum, studia arabica, o studia ebraica, normalmente vitales para la disputa interreligiosa. Junto a ellas las escuelas de traductores (Toledo, Aragón) de enorme importancia en la difusión cultural y el cambio educativo. La labor traductora grecolatina se remonta a la Antigüedad romana y continúa, en cierto modo, en los talleres de los copistas (de gran importancia para la traducción al romance), pero surge una eclosión, sobre todo en Italia y la España, a partir del siglo XII por sus resultados y repercusiones en la traducción árabe-latina y hebreo-latina (Burnett, 1995; Lejbowicz, 2009).

Un signo de la vinculación de las Escuelas con la gestación de la universidad lo vemos en el caso de la extensión de la palabra facultas, décadas antes de que designen un centro de enseñanza especializado en una disciplina, designa al final del siglo XII e inicios del XIII, las diferentes disciplinas enseñadas.

\section{SUJETOS Y AGENTES DE LA EDUCACIÓN MEDIEVAL}

Desde la perspectiva de la finalidad de la educación y su esencialidad podemos ver una transformación en el sujeto de la educación que pasa en la Edad Media por un cambio en el peso social del educando. La educación antigua estaba diseñada de forma especial para las clases aristocráticas y el modelo así resultaba más homogéneo en las etapas formativas. Este modelo se perpetúa en los primeros siglos de la Edad Media, con una mayor intervención del poder público en la existencia de las escuelas, que tienen como finalidad educativa la formación para el desarrollo de las funciones directivas en la vida pública. Esta función pública y el propio control político de las escuelas nunca desaparecerá del todo, incluso una vez la escuela sea una organización, sobre todo, eclesial. 
La Edad Media va transformando el criterio socioeconómico de la finalidad educativa por el pastoral, toda vez que la institución de referencia es la Iglesia. Esto supone que se introduce frente a la finalidad de la promoción social, sea profana - la promoción política, que se puede ver en las élites políticas de los diversos pueblos godos ejemplificado en Casiodoro (ca. 477-562/570) — o religiosa - el acceso a la alta jerarquía eclesiástica copada por los aristócratas - , una nueva finalidad educativa ejemplificada en la acción predicativa de Cesáreo de Arlés (470-542): el hacerse comprender por la mayor parte de las personas, los sujetos reales de la formación. Así el educando se desdobla en el sujeto de la acción predicativa, un educando general, y en el sujeto de la formación para ejercer posteriormente la función predicativa, el clérigo. De modo que habrá una formación de base para el pueblo y una formación más especializada que va formando en lo que serán los agentes de la educación, los protagonistas de la enseñanza de las escuelas.

La apertura a los agentes de la formación no se cierra a las clases privilegiadas. Pudiera ser que las responsabilidades eclesiales se cerraran a la aristocracia, pero la función religiosa (del clero y monástica) se abre, en principio, a todos y eso se hace patente con el paso de los siglos, sobre todo en la educación de las órdenes religiosas. Así en el apogeo de las órdenes monásticas se establece una diferencia entre los letrados y los iletrados cuyo hecho diferencial es el origen familiar y cuyo fin es la función clerical (Grundmann, 1958). Los hijos de los nobles ingresados en los monasterios poseen una formación y de esta forma pertenecen al clero. Es verdad que las reformas posteriores - especialmente la cisterciense - introdujeron el trabajo físico (agrícola) como elemento de popularización, pues la agricultura ocupaba a la mayoría de la gente. Pero este intento no frenó el criterio aristocrático que continuó dividiendo a los monjes en dos grupos: las clases superiores, formando parte del clero y, por lo tanto, con una educación cuidada, y las clases populares, que se ocuparía de realizar los oficios físicos. Este criterio cambiará con la entrada en escena de las Órdenes mendicantes, especialmente los franciscanos. La elección de los hermanos dedicados al estudio no recaerá, por principio, en el origen aristocrático sino en la disponibilidad personal, toda vez que su fundador, Francisco de Asís (de origen burgués) es ejemplo y espejo de comportamiento, valores, perfección y predicación definiéndose así mismo "idiota e iletrado" (el nombre con el que se designaba a los monjes sin estudios y de origen humilde). Lo ocurrido en las Ordenes mendicantes es ya el reflejo de lo que ha pasado con la renovación urbana a partir del siglo XII y que estalla con la creación de las universidades

La relación maestro-alumno es muy personal y de una trascendencia que sobrepasa la instrucción académica, especialmente en el monacato, pero también sucede en las escuelas episcopales. El maestro es a la vez padre espiritual. Uno de los mayores disgustos que podría tener un maestro es que su alumno lo dejara por otro maestro. La relación del maestro con los alumnos es familiar. El maestro enseña sus secretos a los alumnos aventajados que en un futuro serán, ellos, maestros. De modo que lo que capitaliza una escuela no es el nombre de la misma sino el protagonismo del maestro. Uno pertenece más a un maestro que a una escuela. Se conoce en menor medida que sucede en las escuelas presbiterales, o canónicas, donde los alumnos laicos eran más numerosos y la relación entre maestro y alumno no disponía del 
contexto anterior para poder desarrollarse de forma tan estrecha. En el medio urbano se desarrolla una cultura de la educación remunerada. Como señala Verger (1992), en la medida en la que se va imponiendo la enseñanza universitaria el discípulo va dejando paso al estudiante (studens-socius) y el maestro (Marmursztejn, 2007) será llamado doctor (doctor) o profesor (professor).

Otra característica muy importante de la época medieval es el carácter místico-religioso de la acción educativa y de investigación. Es verdad que existen, sobre todo en el ámbito no monástico, intenciones prácticas educativas (promoción en los cargos administrativos públicos y religiosos...) que se acentúan en la medida en que la Edad Media va tocando a su fin y se va "secularizando" la cultura o existe una mayor difusión urbana de la misma a partir del nacimiento de las universidades; pero no es menos cierto que están muy presentes el celo pastoral, la intensidad del deber de formación en cristianos capaces que desempeñen sus capacidades en el seno de la Iglesia e incluso el fortalecimiento íntimo de la fe y la personalidad. Así, por ejemplo, el escriba (scriptor) que trabaja en los talleres de escritura (scriptoria) lo hace frecuentemente por intenciones sobrenaturales, es un medio en el cual se realiza la salvación de su alma, aquí reside su mayor preocupación. El sentimiento religioso del copista o el miniaturista unido a la intención teológico-pastoral son fundamentales y de primer orden, más allá de una intención meramente "intelectual".

\section{CONTENIDO (CURRÍCULO)}

El cuadro normal de estudios en la Edad Media desde el principio es el heredado de las artes liberales. La cosmovisión religiosa cristiana dominante en Occidente no supuso una renovación ex nibilo en la transmisión del conocimiento, más bien al contrario, era algo que pertenecía al propio ser y quehacer del cristianismo el realizar relecturas del mundo heredado y sentirse hombres "cristianos" de su mundo. ${ }^{4}$

Junto al programa común de la enseñanza, las profesiones no eclesiásticas necesitadas de formación contienen, especialmente en los siglos primeros (hasta el s. VIII), un "currículo oculto" que no se limita solo a la instrucción en las escuelas. Jueces y funcionarios, añaden a su educación básica en las escuelas urbanas y, sobre todo, eclesiásticas, una formación profesional basadas en la práctica activa de la profesión a la que se le suma el estudio personal de los textos (estudio al que había sido capacitado en la educación escolar básica mediante el estudio de la gramática) y la enseñanza más precisa y concisa de los más veteranos en el desempeño de la profesión.

4 "Los cristianos, en efecto, no se distinguen de los demás hombres ni por su tierra ni por su habla ni por sus costumbres. Porque ni habitan ciudades exclusivas suyas, ni hablan una lengua extraña, ni llevan un género de vida aparte de los demás... sino que habitan ciudades griegas o bárbaras, según la suerte que a cada uno le cupo y adaptándose en vestido, comida y demás género de vida a los usos y costumbres de cada país". Epistola a Diogneto, n. 5, p. 1-4 (Ruíz, 1979, p. 850). 
Las artes liberales se conciben en la Edad Media como herramienta propedéutica, al estudio de los textos, especialmente la Biblia (también subsidiariamente al comentario de textos jurídicos). En la Antigüedad tardía e inicios de la Edad Media, no existía un currículo específico para los jóvenes cristianos, que estudiaban en las escuelas urbanas y recibían una formación catequética especial en sus comunidades. Con el tiempo irá modificándose. Sin duda alguna, la obra De doctrina christiana de san Agustín será una referencia para los educadores durante el medioevo. San Agustín, educado en los clásicos, gran gramático y retórico, presenta la necesidad del aprendizaje de las letras como requisito para la adecuada educación moral. Esta correspondencia entre enseñanza literaria (humanista) y comportamiento moral será rescatada a lo largo de la Edad Media. Lógicamente surgirán tensiones respecto a la importancia que han de darse a uno y otro polo formativo, sobre todo en lo referente al estudio de la Sagrada Escritura, pues la formación clásica no puede olvidar que su finalidad es el comprender los textos sagrados y transmitir la fe. La apuesta fue confirmada por Casiodoro. ${ }^{5}$ Hay que notar, no obstante, que, aunque el estudio de las artes liberales constituye el núcleo de la enseñanza, en la práctica muchas escuelas sólo impartían - y algunas veces no de forma completa las disciplinas del trivium (escuelas de gramática), seguidas del estudio del bestiario, el lapidario y el herbario, que tuvieron influencia, sin duda, en el desarrollo de las ciencias (geometría y medicina principalmente). ${ }^{6}$

Las artes liberales constaban de dos etapas o partes que se conocen por su nombre latino y que designan el número de disciplinas enseñadas. Se tratan del trivium (tres caminos), es decir la enseñanza de la gramática (comentario de los textos "clásicos"), la retórica y la dialéctica (la lógica) y el quadrivium (cuatro caminos), a saber, la geometría, la aritmética, la astronomía y la música. ${ }^{7}$ En torno a estos estudios se elaboran una serie de manuales (como en la época helenística) y las disciplinas se siguen explicando utilizándose las herramientas conceptuales en formatos similares, sobre todo al inicio de la Edad Media. Los cambios que

5 El autor calabrés, en su obra Institutiones divinarum et saecularium litterarum, presenta los autores que pueden servir mejor para el estudio de la teología y especifica el plan de estudios que puede ayudar a los clérigos, introduciendo la distinción del trivium o ciencias sermonciales y el quadrivium o ciencias reales (Cardini, 2009).

6 El bestiario (bestiarium) es un compendio descriptivo de animales (bestias) que en la Edad Media envolvía una categoría simbólica que acompañaba la exégesis bíblica (Bologna, 1977). El lapidario (lapidum) por su parte recogía las propiedades de las piedras y minerales (Herrera 2005). A ello se acompañaban el herbario (herbarium), un libro de botánica, que describía las plantas y sus propiedades medicinales y que tuvo como fuente principal el tratado médico de Dioscórides, De Materia Medica (Dioscórides/ Pseudo Dioscórides, 1998).

7 Existe una regla nemotécnica desarrollada en la Edad Media sobre las disciplinas de las artes medievales: "Gramm loquitur, Dia verba docet, Rhet verba colorat,/ Mus canit, $A r$ numerat, Geo ponderat, Ast colit astra (La Gram[ática] habla, la Dia[léctica] enseña, la Ret[órica] colorea las palabras/ La Mús[ica] canta, la Ar[itmética] cuenta, la Geo[metría] pesa y la Ast[ronomía] trata de los astros)" (Buisson, 1911). 
se operan no dependen tanto de la finalidad, como de la evolución intrínseca a la propia disciplina. ${ }^{8}$

Alcuino de York marcará la estructura organizativa del currículo en tres grados.

- Enseñanza básica o elemental: centrada en la adquisición de los contenidos curriculares instrumentales básicos: lectura del salterio, escritura, nociones elementales de latín vulgar, comprensión sumaria de la Biblia y de los textos litúrgicos, estudio de cómputo (sobre todo comprensión del calendario litúrgico);

- estudio de las artes liberales (inspirado en Casiodoro): el alumno aprende a realizar una especialización y no la mera utilización de los recursos;

- por último, estudio en profundidad de la Sagrada Escritura.

Varios estudios (Ebbesen y Koerner, 1990; Hunt, 1980) muestran que la herramienta básica que se va a imponer es el latín, lo que supondrá un impulso del estudio de la gramática. El latín se convierte en la lengua vehicular de la enseñanza (e instrumento de unificación), toda vez que la Biblia, el texto fundamental, circulaba en su versión latina a partir de la Vulgata de san Jerónimo y sus respectivas recensiones. ${ }^{9}$ Su preeminencia cristalizará finalmente con Carlomagno y el plan de estudios de Alcuino, al imponer de forma esencial el latín como lengua de cultura. Así la gramática, los glosarios, la métrica poética se estudia de forma cuidada. La promoción del latín fue paralela con la de la literatura y la cultura clásica que conocen en Cicerón un autor de referencia. En la medida que el impulso carolingio va dando paso al protagonismo de la cultura monacal, aunque en Alemania e Inglaterra los príncipes ejercieron con frecuencia cierto mecenazgo, se impone una disputa sobre la utilización del latín como instrumento o también como meta educativa, es decir, si la enseñanza del latín tenía que estar al servicio del estudio de la Biblia o si los contenidos de la Antigüedad tenían valor en sí mismos como objetivos del estudio. En todo caso el latín se estudiará en sí mismo con el bagaje cultural en la medida en que ayuda a comprender mejor la Biblia, permite pervivir la cultura del libro propia de las bibliotecas monásticas (reforma de Lorraine) y la liturgia (reforma cluniacense). En las escuelas urbanas del siglo XII la gramática incide en el gusto por el preciosismo de las letras a partir de los glosarios. Uno de los brazos fundamentales de la gramática fue la etimología o estudio del origen de los nombres, una ciencia que contribuyó a la interpretación de los textos.

8 Obras como Las bodas de mercurio y la filosofía del siglo V o las Instituciones de Casiodoro están presentes en siglos posteriores como parte esencial de la enseñanza de las artes liberales.

9 Por ejemplo, cuando Irlanda, tierra totalmente ajena a la romanización, se convierte al cristianismo hacia el siglo $\mathrm{V}$ no realiza ninguna labor de traducción del texto revelado al celta ("inculturación"), sino que simplemente los responsables de la pastoral y la enseñanza de los principios evangélicos acogen el latín como lengua de enseñanza, predicación y litúrgica. Los anglosajones, más tarde, a ejemplo de lo realizado por los monjes irlandeses, ven en la unidad instrumental del lenguaje y la unidad de la cultura a partir del cristianismo un medio privilegiado de unidad política y cohesión social. 
Junto al estudio del latín, y la gramática, el estudio de la retórica (ars retorica, preceptio oratoria, dictamen) se revela de gran eficacia no solo para la labor predicativa sino para la carrera política y de responsabilidad pública. En la Edad Media la retórica es el arte de enseñar el decir de forma adecuada y ornamentada. Se trata de aquellas partes que se encuentran junto al lenguaje el discurso: la elocuencia, el comentario, el arte poética y de predicación, y todo ello desarrollado como un arte propio, con sus propios tratados (glosas, comentarios, sumas, tratados, florilegios, colecciones...) y enseñados en el aula. Era frecuente ver a príncipes dotados de retórica, y también ver a los grandes maestros de retórica ser promocionados a altos cargos eclesiales, sea obispos o abades, como se recogen en tratados de la época postcarolingia (cf. Libellus scholasticus de Walter de Spire).

Por su parte, la dialéctica va alcanzando cada vez mayor protagonismo, siendo exponente del aperturismo e innovación de las artes, especialmente en las escuelas urbanas del siglo XII. Ejemplificado en Fulbert de Chartres, recupera su espacio a partir de los tratados lógicos (Isagoge de Boecio, Categorías de Aristóteles, los Tópicos de Cicerón y las obras de Boecio). A esta contribución contribuyó enormemente las obras traducidas del árabe. El desarrollo de la lógica camina paralelo al de la ciencia, al constituirse en útil fundamental, pero no sólo ayudó al conocimiento científico. La dialéctica se vuelve, también, un arma fundamental en la instrucción activa donde el alumno (ya más que discípulo) no se conforma con asentir lo que dice el maestro "magister dixit", sino que cultiva la reflexión personal, las preguntas y las objeciones, la discusión.

La lógica o dialéctica era considerado el vehículo fundamental para la enseñanza del conocimiento científico y su elaboración. Su desarrollo supone tanto el despliegue de un vocabulario específico de términos lógicos (predicable, silogismo, falacia, categorema...) como la introducción del método "escolástico", que llegará a revolucionar la metodología y los contenidos de la enseñanza en general y de la enseñanza filosófico-teológica en particular. Paradigma de este cambio es Pedro Abelardo (1079-1142) ${ }^{10}$ quien se rebela abiertamente, y no sin críticas, ${ }^{11}$ contra los métodos docentes al uso. Como veremos después, se opera un cambio en el que la enseñanza de la sacra doctrina supera el horizonte espiritual y el fin de la predicación para ser un medio en el que poder conseguir una racionalización de la misma. La teología implica búsqueda y reflexión y supone una revolución metodológica, propia de la escolástica. El orden sistemático que viene marcado en la historia de la salvación (Biblia) se sustituye por un orden temático racional. Así es como llegan a plantearse problemas filosófico-teológicos, a los que se dan diferentes respuestas dependiendo del razonamiento de cada maestro.

10 Estudia y enseña en París y en sus alrededores. Fue alumno de tres grandes maestros: Roscelino de Compiegne (ca. 1050-1120/1125), Guillermo de Champeaux (ca. 10701122) y Anselmo de Laon (1050-1117).

11 La oposición frontal la encuentra sobre todo de la mano de san Bernardo de Claraval (1091-1153), impulsor del movimiento cisterciense, con una gran influencia en la política eclesial y en la espiritualidad de su tiempo, teniendo su reflejo en la condena del concilio de Sens. 
También es notoria la recuperación de los estudios de las disciplinas del quadrivium impulsado, sobre todo a partir del siglo XI, por el contacto con los textos árabes proporcionados por las traducciones que introducen nuevos textos y constituye una renovación de las fuentes y recuperación de los propios autores griegos como Arquímedes o Euclides y, por lo tanto, el desarrollo de las ciencias, como la geometría. La aritmética en un principio bebe de las obras de Capella, Boecio, Isidoro de Sevilla y parte de la obra de Beda el Venerable, siendo reducida a aritmética especulativa y estudio del cálculo (ábaco y digital). La introducción de los textos árabes de España a partir de Gerberto de Aurillac (el papa Silvestre II, 999-1003), implica el inicio de la introducción de las cifras y el cálculo decimal ("Método de los indios" introducido por Fibonacci, ca. 1170-1250). La labor traductora de Adelardo de Barth fue también de gran trascendencia. A partir del siglo XII, con la renovación conceptual recibida y el empeño unánime de los autores y su voluntad descriptiva, se realiza un desarrollo de esta disciplina que afecta a la vida práctica de forma esencial: comercio, viajes... La astronomía como la disciplina precedente también aprovechará las fuentes antiguas (como M. Capella) y las traducciones árabes. Basada en el paradigma ptolomaico, resulta interesante el desarrollo de instrumentos como el astrolabio (que realiza una proyección estereográfica de los cielos). Por fin, el estudio de la música - que no del canto estudiado para uso litúrgico principalmente -, seguía como fuente original el De institutione musica de Boecio.

Junto a los estudios básicos también surge un estudio cada vez mayor de la medicina y el derecho y en general de las artes mecánicas (artes mechanicae), lo más parecido al moderno concepto de ciencias prácticas o tecnológicas. La ciencia médica se desarrolla profundizando los escritos de Hipócrates (son ejemplares monasterios como Monte Casino, o Salerno). El derecho fue una disciplina que siempre fue estudiada teniendo en cuenta que una de las prioridades de la formación era el estudio de textos legislativos. Pero da un salto de importancia con la recuperación de la codificación justiniana (Bellomo, 1979). Esta junto con la lectura del Digesto y las Pandectas, representan un derecho civil que fue el que recibió Bolonia, centro y clave de la actividad académica. "A su lado, cada vez con mayor abundancia, se registran toda clase de colecciones y estudios sistemáticos del Derecho canónico" (Díaz, 1992, p. 66), especialmente a partir del Decreto de Graciano, como veremos.

\section{MÉTODOS Y RECURSOS}

Si las estrategias educativas discurren en muchas ocasiones paralelas a los medios y recursos disponibles, esto se acentúa en la Edad Media, especialmente en la Escolástica, donde la metodología se vincula especialmente al tipo de recurso escrito utilizado.

\section{TEXTO FUNDAMENTAL: LA BIBLIA Y SU EXÉGESIS}

Teniendo en cuenta el carácter eminentemente eclesiástico de las escuelas medievales no es de extrañar que para formar a un buen clérigo la Biblia se postule 
como texto fundamental. Hemos dicho ya que en ocasiones se platearon polémicas respecto a la utilización per se de textos de autores clásicos de la Antigüedad, pero aún en los momentos en los que estos tuvieron un significado especial, terminaron por ser secundarios frente a la Biblia. Los estudios de Gilbert Dahan (1999) muestra cómo el estudio de la Biblia se realiza frecuentemente a través de instrumentos determinados, a saber, el estudio de los salterios y los textos propios de la liturgia, amén de la propia evolución del texto latino nacido de la Vulgata y sus recensiones.

Para realizar una correcta lectura del texto bíblico, una de las herramientas fundamentales durante gran parte de la Edad Media, especialmente utilizada en las escuelas monásticas, será la lectio. La lectio tiene origen en las fases de la lectura propias (junto a la emendatio, enarratio, iudicium) de los gramáticos helenistas (Varrón, m. 27 d.C.). La intención en la época medieval reside en leer la Escritura para descubrir en ella un nuevo modo de vida. ${ }^{12} \mathrm{~A}$ la lectio divina, se le incorporan dos técnicas hermenéuticas: las glosas y los cuatro sentidos de la escritura. Las glosas van desarrollando una serie de comentarios, que pronto se convertirán en quaestiones teológicas, hasta que éstas pasen a independizarse del texto bíblico y a tener vida propia. Los cuatro sentidos de la escritura tuvieron infinitas variaciones desde Orígenes (185-254) que se expresa plenamente en el dístico de Agustín de Dacia. ${ }^{13}$ Los cuatro sentidos son:

1. sentido literal, los hechos históricos narrados por la Biblia, es decir, la serie de intervenciones de Dios en la historia de la salvación;

2. sentido alegórico, lectura interpretativa de los hechos;

3. sentido moralis o tropológico, para descubrir una orientación segura para regular la vida cristiana según los criterios queridos por Dios; $y$

4. sentido anagógico, que nos abre al conocimiento de las realidades escatológicas. La exégesis bíblica vivió su periodo fundamental en los siglos XI y XII (Hugo de San-Víctor, De Scripturis) perviviendo en el XIII.

\section{INSTRUMENTOS LEXICOGRÁFICOS: GLOSARIOS, VOCABULARIOS Y DICCIONARIOS}

Como hemos señalado, la enseñanza del latín era fundamental como lenguaje universal del mundo de la cultura. Pero lógicamente no era el lenguaje hablado en las diferentes realidades cotidianas. Su estudio era imprescindible. Para ello se utilizaron diferentes recursos como los glosarios, vocabularios y diccionarios, útiles lexicográficos para la enseñanza de la gramática y la retórica.

Los glosarios fueron instrumentos de trabajo muy útiles en la enseñanza y la transmisión del latín. El glosario consistía en una lista de palabras poco

12 En el siglo XII se desarrollan las cuatro fases de la lectio divina: lectura, meditación, oración y contemplación.

13 Cita Henri de Lubac la siguiente frase medieval que señala la importancia de esta técnica: "Littera gesta docet, quid credas allegoria, moralis quid agas, quo tendas anagogia" (Lubac, 1959, p. 23). 
conocidas encontradas en los textos, seguido de breves explicaciones. Podían ser glosarios entre latín-latín o latín-lengua vernácula. Los glosarios ordenaban las glosas (interpretaciones interlineares y marginales de palabras difíciles) de forma alfabética o sistemática, de modo que se constituía en una herramienta de simplificación de gran utilidad. Junto a la utilización de las glosas, evolucionando, aparece el vocabulario (vocabularium) que en un principio trata de una lista de palabras y que en ocasiones es una colección de vocabula en el que se realiza una mayor información, incluso más amplia que la interpretación. Por último, el diccionario (dictionarius o-um) aparece en el siglo XIII, como señalan los estudios (Weijers, 1991) como una colección de términos.

\section{LA UTILIZACIÓN DE TEXTOS: FLORILEGIOS, DECRETOS Y REPERTORIOS}

De entre la diversidad de textos, sin duda alguna destacan los florilegios término más moderno para designar las compilaciones (alphabetum, collectanea, speculum, thesaurus...), es decir, colecciones de citas o extractos de textos, especialmente utilizados en el siglo XIII. Múltiples estudios muestran que los florilegios (Meirinhos y Weijers, 2009, p. XVII-XXXIV) eran variados (literatura, temas académicos o religiosos...) y constituyeron un instrumento de trabajo esencial sobre todo cuando la enseñanza se incrementa en el volumen de alumnado y crece la movilidad.

Los decretos forman parte esencial del mundo jurídico. Es necesario recordar el Decreto de Graciano (Decretum Gratiani o concordia discordantium canonum) en 1140, obra realizada desde los principios canonistas, que desarrolló una auténtica ciencia jurídica (fue una obra muy glosada) y supuso un paso fundamental para la consolidación del derecho canónico en la Edad Media, culminada con los Decretales (Fransen, 1972) promulgados por el papa Gregorio IX en $1244 .{ }^{14}$

Por último, los repertorios o inventarios eminentemente bibliográficos de descriptores e índices de libros son instrumentos de gran importancia en el impulso del libro.

\section{TEXTOS ESCOLÁSTICOS Y METODOLOGÍAS ASOCIADAS}

Alcuino de York establecerá en su estructuración del sistema de enseñanza un conjunto de manuales para cada una de las artes liberales con el fin de asegurar la docencia y el estudio. En ellos se pueden ver las fuentes y limitaciones del impulso carolingio. Estos manuales recogen elementos de los modelos literarios y filosóficos

14 La obra, que formará parte (parte 1) del Corpus iuris canonici, cuenta con cánones pertenecientes a concilios (ecuménicos y locales) de la geografía cristiana y con textos de la Biblia y las fuentes cristianas (Patrística) y clásica. Decretum magistri Gratiani. Ed. Lipsiensis secunda post Aemilii Ludovici Richteri curas ad librorum manu scriptorum et editionis Romanae fidem recognovit et adnotatione critica instruxit Aemilius Friedberg. Leipzig, 1879. 
del mundo clásico yuxtapuestos a las enseñanzas patrísticas. Dentro del trivium las fuentes más citadas son Isidoro de Sevilla, Casiodoro, Beda, Agustín de Hipona, Boecio y Cicerón. Los textos de naturaleza especulativa, es decir, filosófico-teológicos conocen como fuente principal el pensamiento del Obispo de Hipona.

Esta fórmula continuó hasta Pedro Abelardo, un pionero en el desarrollo de la metodología racional para afrontar la problemática filosófico-teológica. Su obra Sic et non recoge de forma aséptica en 158 capítulos sentencias divergentes "ex dictis sanctorum" (padres de la Iglesia) sobre varias cuestiones de la fe y de la moral. En el prólogo expone el método para buscar una solución a las cuestiones planteadas con el único límite de la razón. Herederos en cierto modo de esta nueva metodología racional destacan Graciano, para el derecho canónico y Pedro Lombardo para la teología como señalaba.

Años más tarde, Pedro Lombardo (ca.1095-1160), oyente por algún tiempo en París de Abelardo realizará una obra - el libro de Las sentencias (Libri quatuor sententiarum) - compuesto entre 1155 y 1157 y establecido como libro oficial un siglo más tarde. La obra se trata de una compilación de textos bíblicos con pasajes relevantes de los padres de la Iglesia y muchos pensadores medievales (por citar algunos: san Agustín, Juan Damasceno, Abelardo y Hugo de San Víctor), sobre teología cristiana. Resulta interesante por la selección de pasajes, su intento de reconciliarlos donde parecen defender puntos de vista distintos, y la ordenación sistemática del material. ${ }^{15}$

Los estudios de Boureau (2006) muestran que lo original del texto no estriba sólo en el esquema y el abordaje temático que presenta, sino en la metodología crítica basada en cuestiones y discusiones, y en constituirse en muestra de la trasformación que como demostró Marie-Dominique Chenu (1969) la teología va adquiriendo como ciencia especialmente a partir del siglo XIII. El manual fue el texto base de las universidades medievales, desde 1220 y continuó hasta el siglo XVI, siendo aún comentado con posterioridad. De esta forma, todos los grandes maestros de la escolástica recibieron su influencia, hasta el joven Lutero realiza comentarios sobre el mismo.

De este modo, el estudio de la teología supera la exégesis de la Lectio divina y el sentido de las escrituras, penetrando la divina pagina e introduciendo en la Sacra doctrina elementos racionales donde en un primer momento la philosophia deviene ancilla theologiae y más tarde irá adquiriendo su lugar preeminente no sin recelos con la entrada de la obra aristotélica y el impulso de la filosofía primera.

Ya iniciada la universidad (Glorieux, 1968), eclosiona todo el dinamismo pedagógico y la enseñanza utiliza varias técnicas fundamentales, que aquí sólo enunciamos, especialmente dos: la lectio y la disputatio.

La lectio trataba de una lectura comentada de un texto. Tenía tres fases y tres técnicas: explicación literal (littera) por medio de la divisio; explicación conceptual

15 El libro I trata de la Trinidad, el libro II de la Creación, continúa con Cristo, el salvador de la creación caída, en el libro III, y, por último, en el libro IV, el sujeto de estudio son los Sacramentos, que median para lograr la gracia de Cristo. 
del contenido (sensus) por medio de la expositio; y examen de la significación doctrinal en el contexto (sententia). La lectura podía plantear cuestiones a discutir (dubia) que el maestro utilizaba como técnica de estudio compartido, lo que se conoce como questio. Había dos modelos de lectio. Podía tratarse de la lectura previa de un libro clásico, con un comentario y una paráfrasis, sin más (legere cousoire); o la resolución de problemas planteados por el maestro tras la lectura (legere ordinarie).

Los trabajos de Olga Weijers (2009) han demostrado que la disputatio era una enseñanza en colaboración que consistía en una discusión organizada según un esquema dialéctico. El formato varía según la escuela o facultad en el que se emplease, lo que no varía es la importancia que tiene en lo que llamamos generalmente escolástica. En términos generales, la "disputación" consistía en un debate público entre interlocutores, organizado y que podía provocar las interrupciones de las clases, realizándose normalmente en las épocas litúrgicas fuertes. Las disputaciones podían ser ordinariae, donde era el maestro el encargado de señalar las dificultades, resolverlas y sistematizarlas; o disputaciones generales o quodlibet, de carácter extraordinario, que tenían lugar solamente dos veces al año (Pascua y Navidad), y en las que se debatían los temas más variados, especialmente sobre la base de libros teológicos y de la obra de los santos padres (Frova, 1973, p. 21-22).

Las disputaciones contaban con dos partes determinadas. E1 primer acto lo inauguraba el maestro quien formulaba una cuestión (questio) sobre un texto. Seguidamente los protagonistas eran los diversos actores, uno que formulaba objeciones (opponens) y otro encargado de contraargumentar (respondens). El segundo acto reclamaba el protagonismo del maestro quien avanzaba una solución argumentada y sistemática (determinatio) y daba su solución personal al caso. Días más tarde el profesor mostraba la conclusión (determinatio magistralis) que daba lugar a un escrito conclusivo llamado cuestión disputada (questio disputatio). Alguna vez tenían lugar las disputaciones magisteriales (disputatio magistrorum) donde participaban los maestros y alumnos de la facultad y excepcionalmente se producían debates entre dos maestros en los que asistían miembros de las órdenes o maestros de otras universidades (quaestiones quodlibetales). Esta técnica dio lugar a toda una serie de textos y constituye un estadio avanzado de la metodología medieval (Schabel,2006).

Concluyendo con una breve reflexión, no podemos olvidar que la premisa general del universo medieval viene mediada por sus instituciones fundamentales: la Iglesia, el Imperio y el Feudalismo. Estas se erigen en defensoras de un orden cósmico y de las mediaciones que lo protegen (Merino, 2001, p. 99). Este objetivo general traspasa las aspiraciones medievales y explican el horizonte antropológico y social desde la cosmovisión cristiana asentado en una tradición patrística y humanística. De esta forma la Iglesia y la institución política (Imperio y a partir, especialmente del siglo XIV, los reinos) intentarán asentar unos objetivos educativos determinados para asegurar la propia institución y el papel del educando en la misma. Así la primera misión de la Iglesia en su papel educador consistía, como afirma Hervé Martin, en inculcar a los fieles los contenidos esenciales del dogma y de la moral" (Martin, 1991, p. 100) y poco a poco la política se introduce en la formación, especialmente universitaria al mismo tiempo que el conocimiento escolar (escolástico) proporcionaba instrumentos intelectuales a la hora de pensar 
la política (Verger, 1994). Estos dos elementos son paradigmáticos a la hora de poder entender las relaciones dialécticas intrínsecas existentes en la educación en la que el conocimiento estaba al servicio, utilizando un lenguaje moderno, de una educación basada en competencias.

La educación, por lo tanto, pretendía el crecimiento personal para mejor servir la lectura de la Biblia, en fin, tenía en la búsqueda de la sabiduría cristiana el bastión principal dentro de la acción educativa. Pero este contexto esencial se fue realizando en la búsqueda temporal de fines y objetivos que se concretan dependiendo del medio en el que se desenvuelve.

Los distintos instrumentos de enseñanza que hemos visto supusieron la introducción de herramientas pedagógicas que aunaron la palabra, el gesto del educador y la imagen mostrando una gran eficacia. La utilización y desarrollo de estos recursos pedagógicos llevó a ejercer una pedagogía "fundamentalmente autoritaria incluso cuando ella sabía ser, cuando se lo requería atractiva” (Martin, 1991, p. 114). Cuando el humanismo renacentista realice una renovación antropológica en su visión sobre el orden del mundo y, por lo tanto, en su pedagogía, ello no supondrá un rechazo del orden religioso ni la cosmovisión medieval, pues es en las escuelas y las universidades donde se afirma la libertad del hombre y en algunas escuelas, como la franciscana, el papel predominante de la voluntad frente al entendimiento. Pero es sobre esa base que se plantea una profundización sobre el rol de la libertad sobre las acciones humanas.

En la época del Renacimiento aún se podrá observar que existe un horizonte de reflexión en el orden de la libertad que tiene que ser enseñado, el orden de la virtud, en este caso, el de la salvación eterna en el horizonte divino. La educación se hace una necesidad aún más perentoria en la medida en que cuanto más margen de libertad descubre el hombre ante sí y ante los demás más necesita saber dirigir su espíritu. En este sentido, se revive la tensión entre enseñanza del ejercicio de la libertad y control social, desde la Edad media hasta la ilustración el control se ejercerá en el horizonte de la virtud moral teológica. Con la ilustración la autonomía del hombre se hace mayor, pero a la vez también lo hace el control de la razón sobre el hombre. La lucha entre razón y voluntad que está presente en la educación medieval se decantará por una razón autónoma. La referencia del hombre hacia el universo divino va cambiando hacia el sujeto que vive en la sociedad en la que expresa su humanidad. La educación seguirá con la dialéctica vivida en la Edad Media, pero cambiando el modelo de control social de la comunidad eclesial a la comunidad política y de la razón divina a la humana. De la educación del cristiano se pasa a la educación del ciudadano, pero se continúa con una educación que piensa en un tiempo futuro ya no escatológico sino un tiempo de planificación histórica, de progreso.

La contemporaneidad, a partir del siglo XIX se apegará más al tiempo presente y a la libertad desde la voluntad (como la escuela medieval franciscana) pero desde una voluntad inmanente, histórica y social, del hombre autónomo y auto-referenciado. En este sentido parecería que no tiene ese control social, pero la autonomía humana del hombre se sigue pensando en tanto que ciudadano, lo que supondrá perder en parte su carácter personal. Esto supone que la dicotomía con- 
tinúa: la educación de la libertad voluntarista tiene que hacer buenos ciudadanos. La voluntad es un elemento que debe ser controlado. Si la liberta del hombre ilustrado exigía una educación en la autonomía (atributo de la razón), ahora se exigirá una educación para la autonomía (donde la razón educada deba ayudar a la voluntad que el hombre posee). En este sentido podríamos ir remontando esta dialéctica relación entre educación desde y en la libertad y control y dirección hasta el día presente, llegando a la conclusión con Emilie Osmont (2015) que "La relación libertad/educación aparece en primer lugar como una representación determinada en un momento histórico".

El periodo medieval, a su vez, tuvo la gran virtud de entender el carácter enriquecedor de la educación en el desarrollo de la persona y la sociedad, especialmente vinculado a la capacitación en el trabajo. El hombre, hemos visto, especialmente en la administración social, pero también en oficios, se educa con y para el trabajo (Pancera 2002). La idea del hombre como colaborador en la creación estandarizada en la expresión homo faber implicaba la idea de la responsabilidad autónoma del hombre en la vida del mundo, aunque en un horizonte divino.

Visión moral, descubrimiento de la libertad, tensión con el entorno social (político y religioso), preparación del hombre y del cristiano (y poco apoco del ciudadano), educación para la vida del trabajo en sociedad (artes prácticas y administrativas), artes instrumentales y artísticas (trivium y quadrivium)... elementos que parecen anunciar, con la prudencia de la distancia del tiempo, un aprendizaje par aun hombre que pueda desenvolverse en su tiempo, un "perfil del egresado" (diríamos hoy) que sea capaz de adquirir las "competencias básicas" entendidas estas como el conjunto de conceptos, destrezas y valores que el alumnado pone en marcha al aplicar de forma integrada los contenidos propios de cada enseñanza y etapa educativa. Capacidades, con el fin de lograr la realización adecuada de actividades y la resolución eficaz de problemas complejos, entendidas para su tiempo.

Muy al contrario de lo que puede parecerse en un principio la educación en la Edad Media supone, sin duda, no una etapa inevitable en el progreso humano, sino un periodo imprescindible en la construcción del pensamiento occidental, el desarrollo de la universalidad de la racionalidad y el progreso de la ciencia y de las instituciones académicas necesarias, un auténtico adelanto a un espacio común de educación y el reflejo de la adaptación pedagógica a las exigencias humanas y el contexto social.

\section{REFERENCIAS}

AA. VV. La scuola nell'occidente latino nell'alto medioevo. Settimana del Centro Italiano di Studi sull'Alto Medioevo, 19., 15-21 apr. 1971, Spoleto. Atti... Spoleto: Centro Italiano di Studi sull'Alto Medioevo, 1972.

BARdy, G. Les origines de l'école monastique en Occident. Sacris Erudiri - A Journal of Late Antique and Medieval Christianity, Leuven: Brepols, v. 5, p. 86-104, 1953.

Bellomo, M. Saggio sull'università nell'età del diritto comune. Catania: E. Gianotta, 1979.

Bologna, C. (Ed.). Liber monstrorum de diversis generibus. Milano: Bompiani, 1977. 
Boretius, A. (Ed.). Capitularia regum Francorum 1. In: Monumenta Germaniae Historica. Berlin: Weidmann, 1883.

Boureau, A. La méthode critique e théologie scolastique. Le cas des commentaires des "Sentences" de Pierre Lombard (XIIIe-XIVe siècles). In: Chazan, M.; Dahan, G. La méthode critique au Moyen Âge. Tournhout: Brepols, 2006. p. 167-180.

Buisson, F. (Dir.). Nouveau dictionnaire de pédagogie et d'instruction primaire. Paris: Hachette, 1911.

Burnet, Ch. The institutional context of arabic-latin translations of the Middle Ages: a reassessment of the "School of Toledo". In: Weijers, O. (Ed.). Vocabulary o Teaching and Research Between Middle Ages and renaissance. Proceedings of the Colloquium London, Warburg Institute, 11-12 March 1994. Turnhout: Brepols, 1995. p. 214-235.

Cardini, F. Cassiodoro il Grande. Roma, i barbari e il monachesimo. Milano: Jaca Book, 2009.

Chenu, M.-D. La théologie comme science au XIIIe siècle. 3. ed. Paris: Vrin, 1969.

Clerval, J.-A. Les écoles de Chartres au Moyen Áge (du V au XVI siècle). París: Picard, 1895.

Dahan, G. L'exégèse chrétienne de la Bible en Occident médiéval. Paris: Cerf, 1999.

Delhaye, Ph. Lorganisation scolaire au XIIe siècle. Traditio, Bronx, NY: Fordham University Press, v. 5, p. 211-268, enero 1947.

Denifle, H.; Châtelain, É. (Eds.). Chartularium Universitatis Parisiensis. Paris: Delalain, 1880. v. 1.

Dhuoda, J. M. Manuel pour mon fils. Editión et Traduction de Pierre Riché, Claude Mondesert, Bernard de Vregille. Paris: Cerf, 1975.

Díaz, M. C. Bibliotecas de los reinos hispánicos en el siglo XII. In: Seminário Alfonso VIII y su época: II Curso de Cultura Medieval, Aguilar de Campóo, 1-6 oct. 1990. Madrid: Fundación Santa María la Real Centro de Estudios del Románico, 1992.

Dioscórides/Pseudo Dioscórides. Plantas y remedios medicinales. Obra completa. Madrid: Editorial Gredos, 1998.

Ebbesen, S.; Koerner, K. De Ortu grammaticae. Studies in medieval grammar in memory of Jan Pinborg. Amsterdam. Philadelphia: J. Benjamins Publications, 1990.

Fransen, G. Typologie des sources du Moyen Age occidental. Turnhout: Brepols, 1972. (Les Décrétales et les Collections de Décrétales, v. 2).

Frova, C. Istruzione e educazione nel medioevo. Torino: Loescher, 1973.

García, F. La enseñanza en la Edad Media: aproximación bibliográfica. In: IgLEsia, J. I. (Ed.). La enseñanza en la edad media: X Semana de Estudios Medievales. Nájera: Instituto de Estudios Riojanos, 1999. p. 473-499.

Glorieux, P. L'enseignement au Moyen Âge. Techniques et méthodes en usage à la Faculté de Théologie de Paris, au XIIIe siècle. Archives d'Histoire Doctrinale et Littéraire au Moyen Age, Paris: J. Vrin, v. 35, p. 65-186, 1968.

Grundmann,H.Litteratus-illitteratus. Der Wandel einer Bildungsnorm vom Altertum zum Mittelalter. Archiv für Kulturgeschichte, Nürnberg: Friedrich-Alexander-Universität Erlangen-Nürnberg; Böhlau Verlag, v. 40, p. 1-65, 1958. 
Haskins, Ch. H. The Renaissance of the Twelfth Century. Cambridge: Harvard University Press, 1928.

Herrera, M. E.(Ed.). Marbodo de Rennes. Lapidario (Liber lapidum). Paris: Les Belles Lettres, 2005.

Hunt, R. W. The History of grammar in Middle Ages. Collected Papers. Amsterdam, Philadelphia: J. Benjamins Publications; G. L. Bursill-Hall, 1980.

Lejвowicz, M. (Ed.). Une conquête des savoirs. Les traductions dans l'Europe latine (fin du XIe siècle-milieu du XIIIe siècle). Actes du Colloque organisé à la Fondation SingerPolignac le jeudi 27 novembre 2008. Turnhout: Brepols, 2009.

Lubac, H. Exégèse médiévale: les quatre sens de l'Écriture. Paris: Aubier-Montaigne, 1959.v. 1, p. 23.

Marín, T. Paleografía y diplomática. Madrid: UNED, 1991. v. 1.

Marmursztejn, E. L'autorité des maîtres. Scolastique, normes et société au XIIIe siècle. Paris: Les Belles Lettres, 2007.

Martin, H. L'Église éducatrice. Messages apparents, contenus sous-jacents. Histoire de l'Éducation, Lyoin: Institut National de la Recherche Pédagogique, n. 50, p. 91-117, 1991.

Meirinhos, J.; Weijers, O. Florilegium mediaevale. Études offertes à Jacqueline Hamesse à loccasion de sin éméritat. Louvain-la-Neuve: FIDEM, 2009.

Merino, J. A. Historia de la filosofía medieval. Madrid: BAC, 2001.

Osmont, E. L'Éducation nouvelle et l'idée de liberté: approche trialectique. Éducation et Socialisation, Montpellier: Presses Universitaires de la Méditerranée, n. 37, 2015. Disponible en: <http://edso.revues.org/1212>. Acceso el: 10 feb. 2017.

Pancera, C. La relation entre travail et éducation. Le Télémaque, Caen: Presses Universitaires de Caen, n. 22, p. 105-114, 2002.

Riché, P. La "Renaissance" intellectuelle du Xe siècle en Occident. Cabiers d'Histoire. Revue d'Histoire Critique, Paris: Association Paul Langevin, v. 21, n. 221, p. 27-42, 1976.

Ruíz, D. (Ed.). Epistola a Diogneto. Madrid: Ediciones Cristiandad, 1979.

Schabel, Ch. (Ed.). Theological Quodlibeta in the Middle Ages. The Thirteenth Century. Leiden, New York: Brill, 2006.

Soт, M.; Riché, P. (Eds.). Haut Moyen-Âge: culture, éducation et société. Paris: Publidix,1990.

Verdú, I. La sabiduría como culminación del deseo y del amor en san Bernardo y san Buenaventura. Cauriensia, Cáceres: Instituto Teológico; Universidad de Extremadura y Editorial Sindéresis, v. 9, p. 475-489, 2014.

Verger, J. "Nova" et "vetera" dans le vocabulaire des premiers statuts et privilèges. In: Weijers, O. (Ed.). Vocabulaire des écoles et des méthodes d'enseignement au Moyen Age. Turnhout: Brepols, 1992. p. 191-205.

.Théorie politique et propagande politique. In: LE FORME DELLA PROPAGANDA politica nel Due e nel Trecento. Relazioni tenute al convegno internazionale di Trieste (2-5 marzo 1993). Rome: École Française de Rome, 1994. p. 29-44. 
Verger, J. La Renaissance du XIIe siècle. Paris: Cerf, 1996.

Weijers, O. Dictionnaires et répertoires au Moyen Age. Turnhout: Brepols, 1991.

. Queritur utrum. Recherches sur la "disputatio" dans les universités médiévales.

Turnhout: Brepols, 2009.

\section{SOBRE EL AUTOR}

Manuel Lázaro Pulido es doctor en filosofía por la Universidad Pontificia de Salamanca (España). Investigador de la Universidad Bernardo O'Higgins (Chile) e Profesor de la Universidad Nacional de Educación a Distancia (España).

E-mail:mlazarop@fsof.uned.es

Recibido el 31 de agosto de 2016 Aprobado el 21 de marzo de 2017 